\title{
Liver Cancer pN0 TNM Finding v6
}

National Cancer Institute

\section{Source}

National Cancer Institute. Liver Cancer pNO TNM Finding v6. NCI Thesaurus. Code C61176.

Liver cancer with no regional lymph node metastasis. (from AJCC 6th Ed.) 